\title{
Effective Management of Leakage in Drinking Water Network
}

\author{
R. KILIÇ* \\ SASKİ Genel Müdürlüğü, Kentpark İçi, PK 144, Adapazarı, Sakarya, Turkey
}

\begin{abstract}
There has been an increase in water demand due to the very rapid increase of the world population and industrialization in the last 200 years. However, there are limited available water resources in the world. In addition to this, some of the existing water resources have been unusable due to agricultural and industrial pollution. The need for more effective drinking water network operation becomes prominent in order to fulfil the increasing water demand. In this study, it has been aimed to decrease the leakages and prevent water loss by applying pressure management in drinking water distribution network taking the pressure in the distribution system under control.
\end{abstract}

DOI: 10.12693/APhysPolA.130.479

PACS/topics: 47.27.nf

\section{Introduction}

Water management is defined as the development, distribution, and usage of water resources in a planned manner. It includes such activities as the political and technical decisions on the development of the water resources, the rules regulating water rights and water allocation, environmental protection, regulations on the pricing of water, land use principles and the participation of the users [1].

The developments in the past ten years have brought the "integrated water resources management" principles to the fore in the resolution of world water crisis. In this context, the European Union also shaped its water policies, and declared that the basin-based management approach is adopted with the "Water Framework Directive (WFD)" (2000/60/EC) that came into force in December 2000. The Directive aims to protect and control the water resources within the boundaries of the whole EU, not only quantitatively but also qualitatively. Consequently, a comprehensive policy was put forth in order to protect the European waters by a common standard [2].

In this respect, it is very important to take the physical water losses that occur in drinking water networks under control in the effective and active management of the present resources. The main reason of the water losses that occur in drinking water networks is the network bursts. The most effective method used in taking the bursts under control is to take the pressure in the distribution network under control.

Leakage in distribution systems can be caused by a number of different factors. Some examples include bad pipe connections, internal or external pipe corrosion or mechanical damage caused by excessive pipe load (e.g. by traffic on the road above or by a third party working in the system). Other common factors that influence leakages are ground movement, high system pressure and

*e-mail: recep.kilic@adasu.gov.tr damage due to excavation, pipe age, winter temperature, defects in pipes, ground conditions and poor quality of workmanship.

Leakage is dependent on system pressure. Basically, the higher the pressure, the larger the leak flow and vice versa. Pressure reduction in water distribution systems is normally achieved through pressure reducing valves. The objective of pressure reduction is to ensure the target pressure at any given zone(area) node satisfies the customers. When pressure reduction is made dynamically over a period of time, some computer algorithm/program can definitely make this step easier.

Active leakage policy involves the techniques like: active leakage control and active pressure management. The most appropriate leakage control policy will mainly be dictated by the characteristics of the network and local conditions, which may include financial constraints on equipment and other resources. Active pressure management has been called a well proven method that has an effect on the whole network or pressure zone [3].

A great advancement has been achieved in recent years in the development of new and understandable methods in the determination of the effect of pressure on losses that result from bursts and leakages in the drinking water distribution network. In the studies carried out in developed countries such as the UK and Japan, it was seen that pressure is one of the main reasons of the bursts and leakages. The effect of pressure on leakages was examined by gradually reducing the output pressure in the distribution network. In general, it was seen that the decrease in the system pressure results in the decrease in the amount of water given to the network at night [4].

Drinking water networks are designed in such a way that enough pressure is supplied to the system even during the hours when the consumption throughout the day is highest, even increases due to friction losses and the input pressure decreases. As a result of this design, they are exposed to more pressure than necessary during the other time period when pressure is not needed. Thus, the bursts in most networks occur late at night and early in the morning when the pressure is the highest [5]. The sustainable management of the infrastructure through 
pressure management, and thus reducing bursts and water losses resulting from these bursts have started to be used by institutions performing water management in many countries. The reduction of the bursts and water losses through pressure management can be defined as "the practices in which the system pressure is managed by reducing the excessive and unnecessary pressure that causes leakages and bursts in drinking water distribution networks to levels that do not cause any negativities in the subscribers" [6].

The frequency of the bursts that occur in the network is about how good or bad the pressure is managed. The replacement of the network with frequent bursts is not the one and only option in the reduction of the bursts and repair costs [7].

Drinking water distribution systems are designed in such a way that the network is in integrity with all the connections and fittings for the prevention of leakages and bursts and effective operation. However, this situation cannot be achieved in the applications at all times. Sometimes even a newly manufactured pipe may not be of homogeneous structure. Uniform thickness cannot be achieved in some part of the pipe by reason of construction faults. When the covering around the pipe is not carried out appropriately while laying the pipes, it becomes weak against traffic load, corrosion and other impacts. Tears and cracks occur when the pipe is exposed to pressure in this situation and similar situations. The fluctuations resulting from the pressure in the distribution system may lead to bursts although they occur for a very short time. One of the first practices that must be carried out is to check the pressure fluctuations through measurements carried out in the field [8].

\section{Material and method}

The water source of Adapazaricity centre is Lake Sapanca. Pure water supplied from Lake Sapanca is sent to the tanks in Esentepe using motopumps. It is transmitted to Maltepe Drinking Water Treatment Plant from here using gravity distribution lines. Increased water is supplied to the network under gravity from tanks at an elevation of $104 \mathrm{~m}$. The elevation of the city centre is around $30 \mathrm{~m}$. However, water is supplied via elevated tanks to the upper parts of Maltepe and Hizırtepe districts where the treatment plant and tanks are located are at the same elevation with the tank. Water is compressed into the tank from the main tank via two electro motopumps with a flow rate of $Q=30.50 \mathrm{l} / \mathrm{h}$, pump head of $H_{m}=62 \mathrm{~m}$ and power of $N_{m}=50 \mathrm{~kW}$.

Adapazaricity network is made of high density polyethylene (HDPE) pipe. The network was completely renewed after 17 August 1999 Gölcük earthquake. Maltepe and Hizırtepe districts operate independently from the whole distribution system and one another. Hizırtepe network, where the pressure can be controlled by reducing in order to be able to examine the effect of pressure on bursts and leakage-related water loss, was chosen as the field of application. The length and diameter of the network in the application area are shown in Table I.

TABLE I

The length of the network in the application area by diameters.

\begin{tabular}{c|c|c|c|c|c}
\hline \hline Diameter [mm] & $\varnothing 280$ & $\varnothing ~ 225$ & $\varnothing ~ 180$ & $\varnothing ~ 125$ & Total \\
\hline Length [m] & 344 & 246 & 482 & 9.322 & 10.394
\end{tabular}

Before starting to work in order to determine the current situation in the application area, the subscriber at the highest floor of the highest building in the area was accepted as the critical point and the pressure there was measured and recorded. The critical point was taken as a reference in such a way that no negativity is experienced in the service quality of the water supplied to the subscribers. The output pressure was set to the desired level using pressure control valve. The pressure was measured again and recorded after the application in the subscriber at the critical point. Spontaneous pressure measurements were made in different points of the network in order to confirm whether the pressure change has a negative effect on the subscribers.

The network was modelled using EPANET program in order to determine the effect of the pressure changes that will occur in the network. The pressure values at the nodal points in the network in the current state were seen by operating the model. Pressure values were observed in the model created by setting the output pressure of the pressure regulating valve (PRV) to $30 \mathrm{~m}$ and restarting the model.

The water supplied to the network was measured, and pinpointing the point of leakage works was carried out by examining lowest night flow rates. More effective pressure management methods were applied in the network after the bursts were determined.

\section{Findings and discussion}

The maximum elevation of Hizırtepe application area is $80 \mathrm{~m}$, minimum elevation is $56 \mathrm{~m}$, the elevation of the floor where the tank supplying water to the network is $104 \mathrm{~m}$, and the height of the tower is $35 \mathrm{~m}$. Considering the piezometer line, the pressure is around $83 \mathrm{~m}$ in the area with the lowest elevation of the network. It was seen that the pressure reaches these levels with spontaneous measurements. The pressure is around 56-59 m at the highest elevated areas of the network. The pressure measured at the highest floor of the highest building determined as the critical point is maximum $46 \mathrm{~m}$ and minimum $40 \mathrm{~m}$. The pressure levels measured in the subscriber at the critical point are shown in Fig. 1. There is approximately $15 \mathrm{~m}$ of distance between the pressure measured from the network and that measured in the critical point.

The physical loss at the operation area is quite high. It was understood that the reason for the physical loss is 


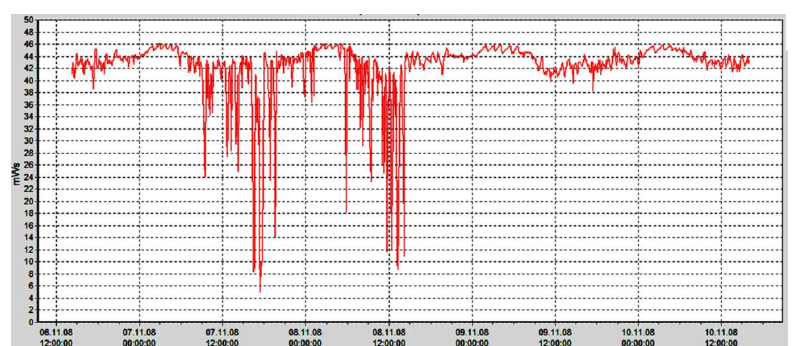

Fig. 1. Pressure measured at the critical point before the application.

the leakages that are formed as a result of frequent bursts in the flow rate and pressure measurements.

Pressure management was applied in order to take the pressure under control in order to reduce the bursts that occur and prevent the leakages.

The pressure values that are expected to be formed in the network in the present situation were simulated in the model using EPANET program. The pressure values that are expected to occur in the model formed are shown in Fig. 2.

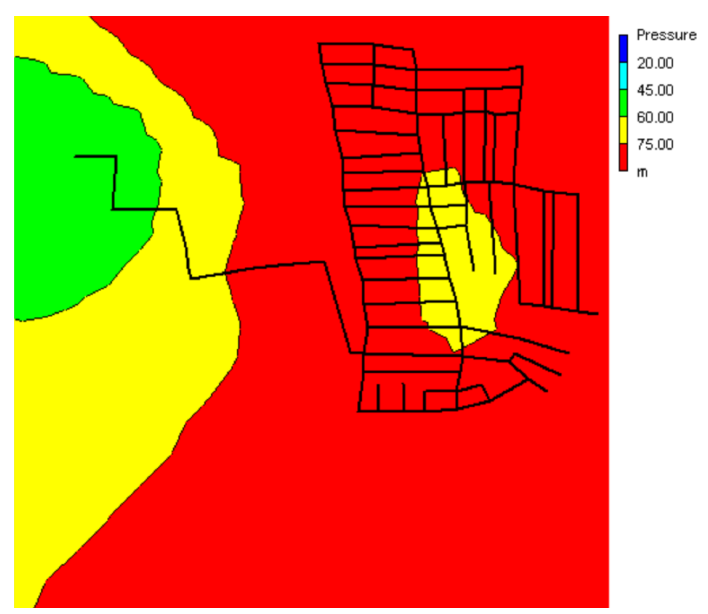

Fig. 2. Pressure values formed in EPANET network model.

The pressure mounted into the network, PRV output pressure was set to $30 \mathrm{~m}$. The pressure was recorded once again from the critical point after adjustment. In Fig. 3, it is seen that the pressure is minimum $18 \mathrm{~m}$ and maximum $23 \mathrm{~m}$ on average. Instant measurements were also taken from different points of the study area, and the subscribers did not make any complaint.

The pressure values that must be formed after PRV output pressure in the network vary between 33 and $38 \mathrm{~m}$ at the highest area by consumption (Fig. 4).

The leakage pinpointing works were carried out by examining the amount of water supplied to the network. A decrease was observed in the amount of water supplied to the network after each the leakage pinpointing (Figs. 58).

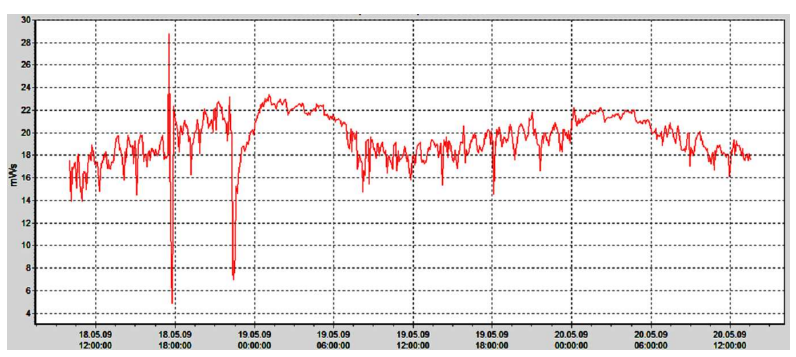

Fig. 3. Pressure measured at the critical point after the application.

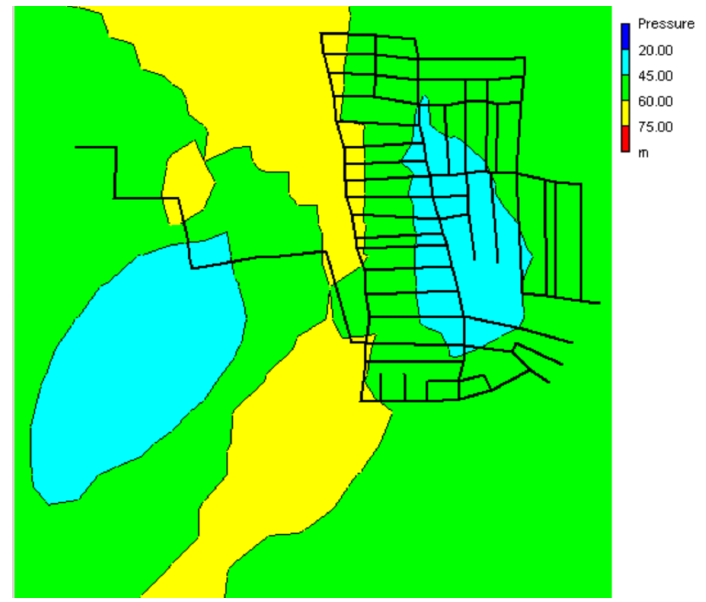

Fig. 4. The pressure values expected to be formed after PRV in EPANET network model.

It was decided that pressure can be reduced in the pressure management can be reduced a bit more after the leakage pinpointing, and the output pressure of the system was reduced $5 \mathrm{~m}$ more (Fig. 9). No change was observed in the service quality of the subscribers after this change. It is understood that the pressure changes more than necessary as a result of the bursts from the

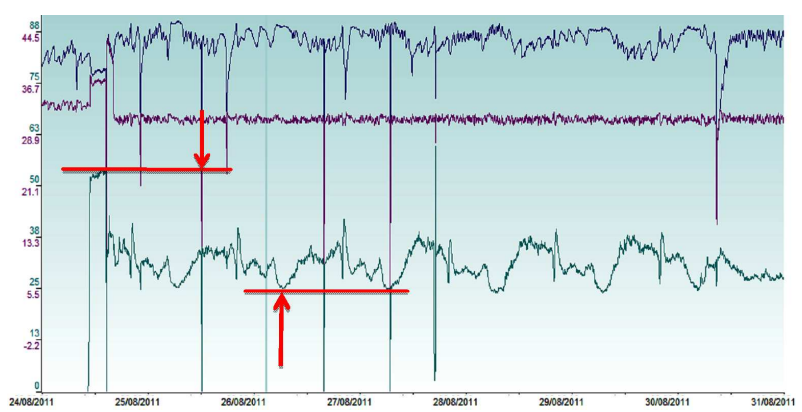

Fig. 5. Pressure and flow rate change in the area after the leakage pinpointing. Pressure management has been started when feed pressure at the critical point is at least $20 \mathrm{~m}$. Flow gain is $15 \mathrm{~L} / \mathrm{s}$. Flow $[\mathrm{L} / \mathrm{s}]$ - top values, pressure [m water head] - bottom values. Principal time marks at $12 \mathrm{AM}$ 


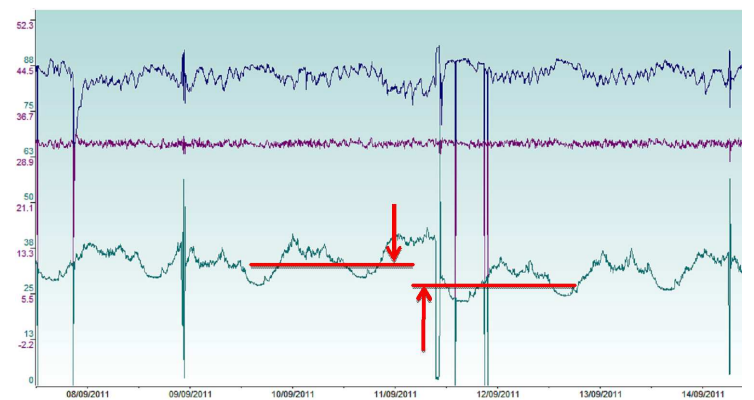

Fig. 6. Flow rate change in the area after the leakage pinpointing. Flow gain is $15+3=18 \mathrm{~L} / \mathrm{s}$. Principal time marks at $5 \mathrm{PM}$.

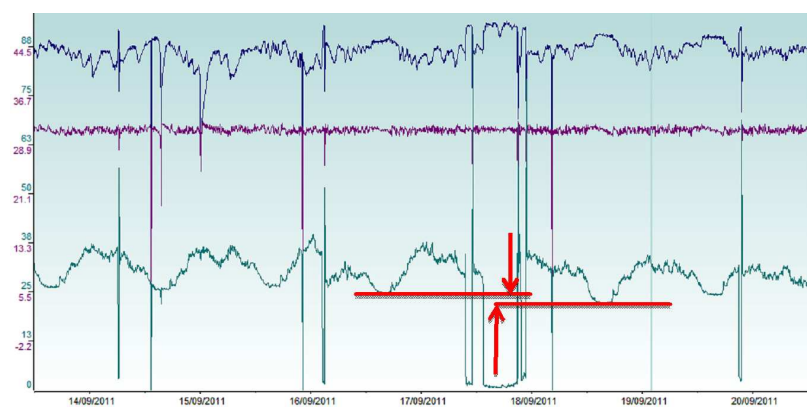

Fig. 7. Flow rate change in the area after the leakage pinpointing. Flow gain is $18+2=20 \mathrm{~L} / \mathrm{s}$. Principal time marks at 5 PM.

fact that no change occurs in service quality although the pressure was reduced in the network.

Repairs were made by determining new bursts and making new investigations in the network (Fig. 10).

It was decided that flow rate controlled pressure management can be used after the repair of all bursts, and adjustment was made in a way that the pressure is $22-$ $30 \mathrm{~m}$ subject to consumption via the control unit used (Fig. 11). It was observed that the formation of new bursts occur less after the adjustment. A decrease of $35 \mathrm{l} / \mathrm{s}$ in total was ensured in the amount of water supplied to the network. The loss of daily $3024 \mathrm{~m}^{3}$ of water

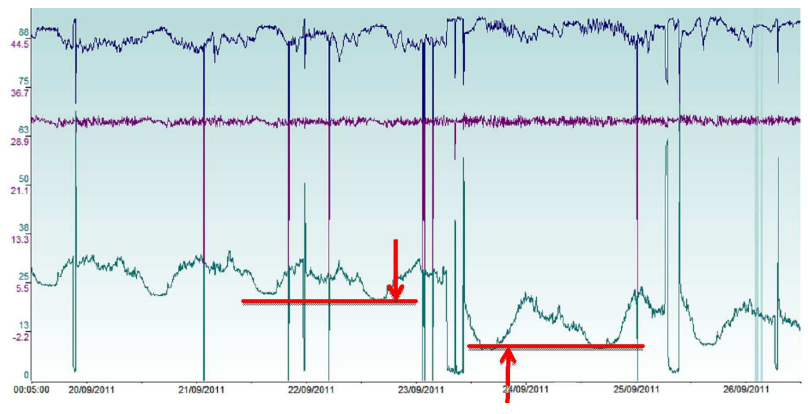

Fig. 8. Flow rate change in the area after the leakage pinpointing. Flow gain is $20+12=32 \mathrm{~L} / \mathrm{s}$. Principal time marks at $5 \mathrm{PM}$.

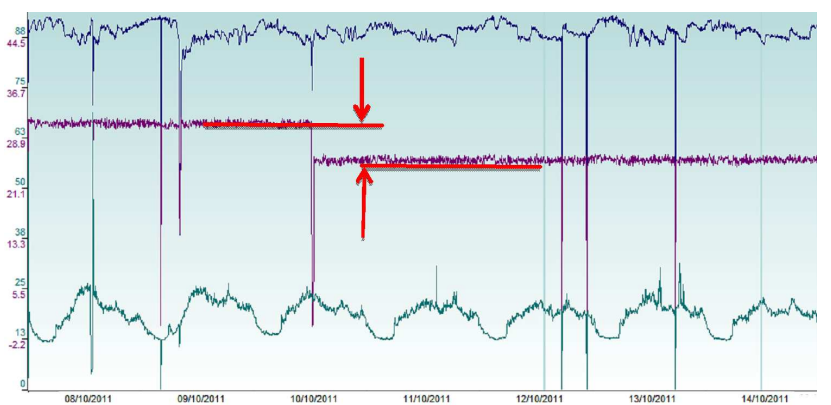

Fig. 9. Reducing the pressure in the area after the leakage pinpointing. Pressure change is $5 \mathrm{~m}$ of water head. Principal time marks at 10 PM.

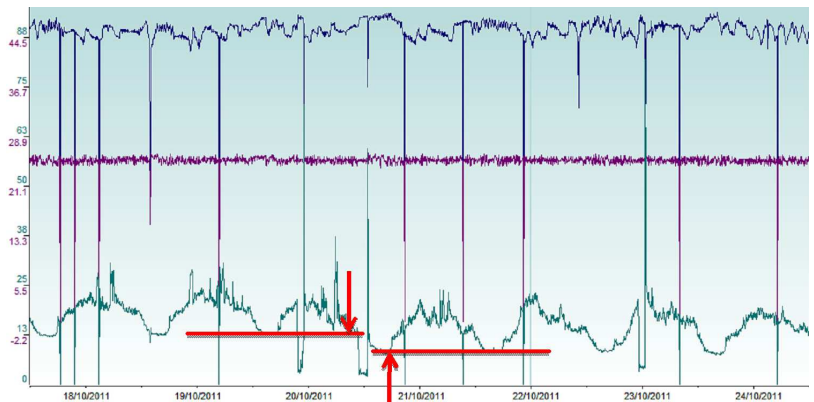

Fig. 10. Flow rate change in the area after the leakage pinpointing. Flow gain is $32+3=35 \mathrm{~L} / \mathrm{s}$. Principal time marks at $10 \mathrm{PM}$.

in the network related to the burst was prevented through flow rate sensitive pressure control.

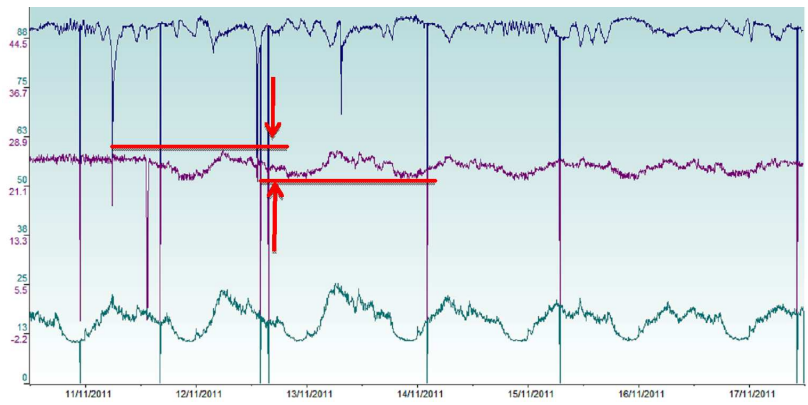

Fig. 11. Output pressure after flow rate sensitive pressure management on condition that the feed pressure at the critical point is at least $20 \mathrm{~m}$. Changes between 22 and $30 \mathrm{~m}$. Principal time marks at 6:44 AM.

\section{Conclusion}

The bursts and the amount of leakage vary by pressure in the drinking water distribution system. Unnecessary and excessive pressure in the network increases the risk of burst. The risk of burst will be reduced, new bursts will be prevented and repair costs will be eliminated as no burst occurs by performing pressure 
management through separating the system into different pressure control points in itself considering the contour curves. Burst-related water losses will be prevented when the new burst period is reduced in the drinking water distribution network. The most efficient control in the drinking water distribution networks is the flow rate related pressure management. The network should be managed via flow rate sensitive pressure control in order for the network can be operated in a sustainable manner, effectively controlled and the losses can be prevented.

\section{References}

[1] E. Özkan, Türk Bilimsel Derlemeler Dergisi 6, 150 (2013) (in Turkish).
[2] Environment and Sustainable Development Thematically, Panel Report No. 25, 2003.

[3] R. Puust, Z. Kapelan, D.A. Savic, T. Koppel, Urban Water J. 7, 25 (2010).

[4] A. Marunga, Z. Hoko, E. Kaseke, Zimbabwe Phys. Chem. Earth 31, 763 (2006).

[5] R.S. Mckenzie, W. Wegelin, in: Leakage 2005 Conf. Proc., Halifax 2005, p. 382.

[6] R. Kilic, H. Cinal, N. Ogleni, Sci. Res. Essays 6, 3595 (2011).

[7] J. Thornton, A. Lambert, Leakage 2005 Conf. Proc., Halifax 2005, p. 1.

[8] J. Morrison, S. Tooms, D. Rogers, District Metered Areas Guidance Notes, IWA, 2007. 